\title{
Contemporary extracorporeal membrane oxygenation therapy in adults: Fundamental principles and systematic review of the evidence
}

\author{
John J. Squiers, BSE, ${ }^{a}$ Brian Lima, MD, ${ }^{b}$ and J. Michael DiMaio, MD ${ }^{a, b}$
}

\begin{abstract}
Extracorporeal membrane oxygenation (ECMO) provides days to weeks of support for patients with respiratory, cardiac, or combined cardiopulmonary failure. Since ECMO was first reported in 1974, nearly 70,000 runs of ECMO have been implemented, and the use of ECMO in adults increased by more than $400 \%$ from 2006 to 2011 in the United States. A variety of factors, including the 2009 influenza A epidemic, results from recent clinical trials, and improvements in ECMO technology, have motivated this increased use in adults. Because ECMO is increasingly becoming available to a diverse population of critically ill patients, we provide an overview of its fundamental principles and a systematic review of the evidence basis of this treatment modality for a variety of indications in adults. (J Thorac Cardiovasc Surg 2016;152:20-32)
\end{abstract}

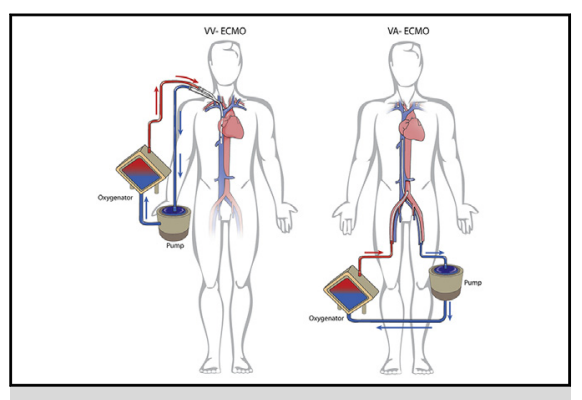

Commonly implemented venovenous (WV) and venoarterial (VA) extracorporeal membrane oxygenation circuit cannulation schemes.

Central Message
We provide an overview of the fundamental
principles of extracorporeal membrane
oxygenation and a systematic review of the
evidence basis of this treatment modality for a
variety of indications in adults.
Perspective
A variety of factors, including the 2009 influ-
enza A epidemic, results from recent trials,
and improvements in technology, have moti-
vated increased use of ECMO. We provide a
systematic review of the evidence basis for a
variety of ECMO indications in adults because
ECMO is increasingly becoming available to a
diverse population of critically ill patients.

See Editorial Commentary page 32 .
Whereas standard cardiopulmonary bypass is designed to ensure minutes to hours of support for patients undergoing surgery, extracorporeal membrane oxygenation (ECMO) provides support to patients with respiratory, cardiac, or combined failure for days to weeks. For patients with isolated respiratory failure, venovenous (VV) ECMO is typically employed to provide support while the lungs

From the ${ }^{a}$ Baylor Research Institute, Baylor Scott \& White Health; and ${ }^{b}$ Department of Cardiac and Thoracic Surgery, Baylor University Medical Center, Baylor Healthcare System, Dallas, Tex.

Received for publication Oct 28, 2015; revisions received Jan 30, 2016; accepted for publication Feb 28, 2016; available ahead of print April 5, 2016.

Address for reprints: J. Michael DiMaio, MD, Baylor Research Institute, 3310 Live Oak, Ste 501, Dallas, TX 75204 (E-mail: jmdimaio@yahoo.com). $0022-5223 / \$ 36.00$

Copyright (c) 2016 by The American Association for Thoracic Surgery http://dx.doi.org/10.1016/j.jtcvs.2016.02.067 recover. Venoarterial (VA) ECMO is available for cases of cardiac or cardiopulmonary failure. The Extracorporeal Life Support Organization is an international consortium of health care institutions that maintains a registry of ECMO use. As of January 2016, the Extracorporeal Life Support Organization has captured more than 73,000 ECMO implementations, with more than 19,000 in adult patients (Figure 1). ${ }^{1}$ The volume of adult ECMO cases increased by $433 \%$ from 2006 to 2011 in the United States, ${ }^{2}$ with corresponding increases in expenditures and resource use. $^{3}$

The use of ECMO in adults has expanded due to several factors: the global pandemic of the novel influenza A virus led to an a higher incidence of acute respiratory distress syndrome (ARDS) refractory to conventional therapy ${ }^{4}$; improvements in technology allowed more successful applications of $\mathrm{ECMO}^{5}$; an infrastructure of specialized 


\section{Abbreviations and Acronyms \\ ARDS $=$ acute respiratory disease syndrome \\ $\mathrm{C}-\mathrm{CPR}=$ conventional cardiopulmonary resuscitation \\ $\mathrm{E}-\mathrm{CPR}=$ extracorporeal cardiopulmonary resuscitation \\ $\mathrm{ECMO}=$ extracorporeal membrane oxygenation \\ LVAD $=$ left ventricular assist device \\ PGD = primary graft dysfunction \\ PCS $=$ postcardiotomy shock \\ $\mathrm{VA}=$ venoarterial \\ $\mathrm{VV}=$ venovenous}

centers, capable of transporting patients requiring ECMO from outside facilities to their intensive care units, has been developed ${ }^{6}$; and a prospective randomized controlled trial recently promoted the efficacy of ECMO in adults with ARDS. ${ }^{7}$ Because ECMO is increasingly becoming available to a diverse population of critically ill patients, it is appropriate to highlight the fundamental principles of this therapy and systematically review the evidence basis for ECMO across a variety of indications.

\section{ECMO CIRCUITS AND EQUIPMENT ECMO Circuits}

The basic ECMO circuit consists of a blood pump, the membrane oxygenator, conduit tubing, a heat exchanger, and drainage and return cannulae. The circuit drains blood from the venous system and pumps it through a membrane oxygenator before returning newly oxygenated blood to the patient. By facilitating oxygen and carbon dioxide exchange, ECMO allows for reduction of ventilator settings to diminish the potential for lung injury. The major difference between VA and VV ECMO circuits is the types of cannulae and location of their insertion.

\section{Modes of Vascular Access}

VA ECMO is designed to provide cardiac support in addition to respiratory support. Deoxygenated blood is drained from the venous system, and oxygenated blood is returned into the arterial circulation, in a similar fashion to standard cardiopulmonary bypass. The pulmonary circulation is bypassed by placing the artificial lung in parallel with the native lungs. ${ }^{8}$ Cannulation can be obtained centrally (blood drained directly from the right atrium and returned to the proximal ascending aorta) or peripherally (blood drained from the proximal femoral or jugular vein and returned to the carotid, axillary, or femoral artery), typically using the Seldinger technique via an open or percutaneous approach. ${ }^{9}$ In cases of femoral arterial cannulation, a high risk of distal limb ischemia has motivated many centers to place an ipsilateral perfusion catheter proactively. ${ }^{10,11}$
During ECMO support in the setting of severe myocardial dysfunction, the left atrial and left ventricular end-diastolic pressures can increase to extremely high levels. To prevent left heart distention, a transseptal drainage cannula can be placed to decompress the left atrium $^{12}$ or an Impella 2.5 (Abiomed, Danvers, Mass) left ventricular assist device (LVAD) can be placed to unload the left ventricle. ${ }^{13,14}$ The successful management of a case of acute cardiopulmonary failure with a hybrid configuration of VV ECMO and an Impella 5.0 (Abiomed) was recently described, as well. ${ }^{15}$ Although this hybrid configuration offered the advantage of uncoupling heart and lung recovery, more evidence is required before its use should become routine. VA ECMO remains the best option for acute cardiopulmonary arrest due to the rapidity with which it can be deployed. ${ }^{16}$ After initiation of VA ECMO, clinicians can confirm successful decompression of the left heart using echocardiography.

Another important consideration for peripherally cannulated VA ECMO is monitoring of cerebral oxygenation. In patients with both poor heart and lung function, oxygenated blood returning from the ECMO circuit will initially provide antegrade flow beyond the site of arterial cannulation and retrograde flow to the coronary and cerebral circulations. As heart function improves, competitive flow between native cardiac output and the arterial cannulation may cause a distal shift in the location of blood mixing. Even when ECMO flow is adequate and the oxygenator is functioning properly, this shift can result in deoxygenated blood circulating through the coronary and cerebral circulations if lung function remains poor or ventilator settings are inadequate. Peripheral blood gas monitoring through the right radial artery (except in cases of right common carotid or right axillary artery cannulation) can be employed to detect coronary and/or cerebral hypoxemia and to guide ventilator and ECMO circuit management. ${ }^{17}$

VV ECMO is designed to provide partial or complete respiratory support without any cardiac support, so VV ECMO is indicated only when native cardiac output is sufficient. VV ECMO places the native lungs in series with the artificial lung. ${ }^{8}$ In adults, several cannulation options currently exist. Traditionally, deoxygenated blood is drained from a femoral vein and returned to the right internal jugular vein. ${ }^{18}$ More recently, a bicaval dual-lumen catheter has been developed to provide both drainage and return directly into the right atrium via the internal jugular vein. ${ }^{5}$ Potential benefits of the single cannulation technique include reduced recirculation (the phenomenon of oxygenated blood returning from the ECMO unit being drained immediately by the outflow cannula, creating a closed extracorporeal circulatory loop that decreases systemic oxygenation), liberation of the femoral vein to allow patient mobility, and reductions in cannulation site infection risk. For patients in whom internal jugular vein access is not available, bifemoral vein 

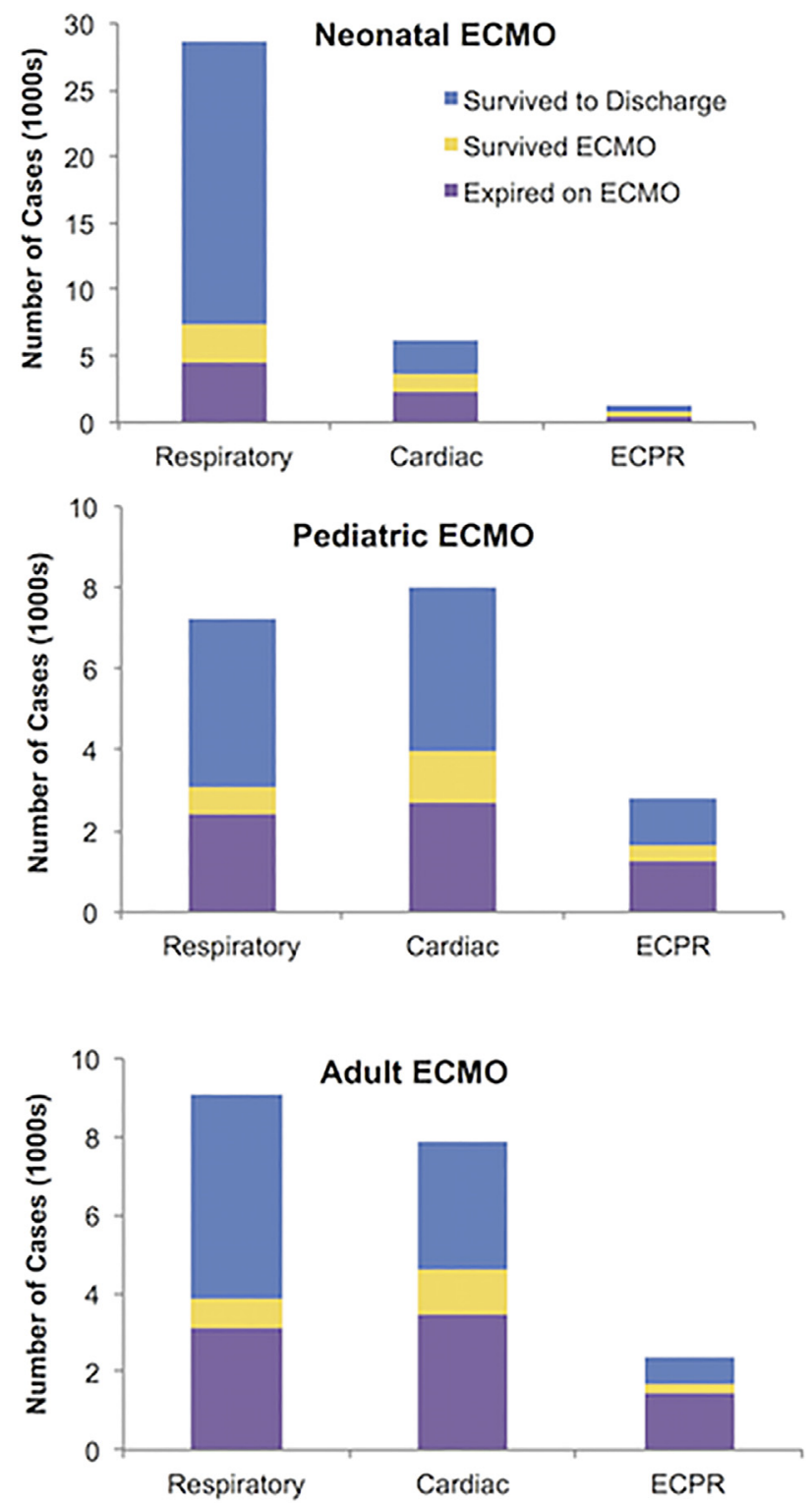

FIGURE 1. Outcomes of all extracorporeal membrane oxygenation cases recorded by the Extracorporeal Life Support Organization (ELSO) from 1985 through 2015, organized by cardiac, respiratory, and cardiopulmonary resuscitation (E-CPR) indications. ECMO, Extracorporeal membrane oxygenation; $E C P R$, extracorporeal cardiopulmonary resuscitation.

cannulation with drainage from the inferior vena cava and return to the right atrium is another option. Echocardiography and fluoroscopy can be implemented to assess for proper cannula placement in VV ECMO. A diagram of common cannulation schemes for both $\mathrm{VA}$ and $\mathrm{VV}$ ECMO is presented in Figure 2.

\section{Oxygenators and Pumps}

ECMO oxygenators serve as artificial lungs to exchange both oxygen (to blood) and carbon dioxide (from blood) in place of the patient's native lungs. During the past decade, a new generation oxygenator that combines the advantages and eliminates the disadvantages of previous machines has been introduced. The oxygenator incorporates a nonmicroporous polymethylpentene membrane into a hollow fiber structure. Polymethylpentene oxygenators have been associated with reduced red blood cell and platelet transfusion requirements, improved gas exchange, and greater durability than older units. ${ }^{19}$

Two types of pumps are currently available in ECMO units: roller and centrifugal (constrained vortex) pumps. Centrifugal pumps, which are smaller, move blood by creating a pressure differential across a pump head that contains a magnetically driven impeller spinning at up to 3000 revolutions/min. Roller pumps move blood by progressively compressing segments of tubing along a curved raceway. Centrifugal pumps have been associated with a lesser degree of hemolysis compared with roller pumps, and therefore the use of these pumps in adult patients is increasing. ${ }^{20}$ However, a recent retrospective analysis demonstrated an increased risk for nonsurgical bleeding (gastrointestinal, pulmonary, and neurological) with centrifugal pumps despite lower levels of heparin anticoagulation. ${ }^{21}$

\section{HISTORICAL FOUNDATION}

Maximilian von Frey built the initial prototype heart-lung machine in $1885,{ }^{22}$ but surgeon John Gibbon and his wife Mary were the first to develop a heart-lung machine that facilitated successful open heart surgery. ${ }^{23}$ The Gibbons' heart-lung machine consisted of a simple blood pump for an artificial heart and direct exposure of the flowing blood to oxygen gas as the artificial lung. The direct exposure of blood to gas caused significant hematologic damage that limited the use of this machine to only 2 to 3 hours. ${ }^{24}$ The insertion of a gas exchange membrane between flowing blood and the oxygen source prevented massive blood trauma and allowed for prolonged use of heart-lung machines. ${ }^{25}$ The first membranes required large surface areas that were impractical for clinical application, but in the 1960s the synthesis of silicone rubber allowed for the miniaturization of the membrane and clinical use of the heart-lung machine for much longer periods of time. ${ }^{26}$

The first human implementation of prolonged cardiopulmonary bypass (ie, ECMO) was reported in 1972 by Hill and colleagues. ${ }^{27}$ The authors described a 24 -yearold man who developed respiratory failure following aortic repair surgery for subadventitial transection of the thoracic aorta in a motor vehicle accident. The patient's respiratory failure worsened despite maximal conventional supportive therapy, so partial VA perfusion was initiated. After 75 hours, the patient's respiratory failure had improved such that he could be successfully weaned from ECMO, and the ${ }^{28}$ reported a series of 28 patients (14 pediatric and 14 adult) who were treated with ECMO shortly thereafter. 

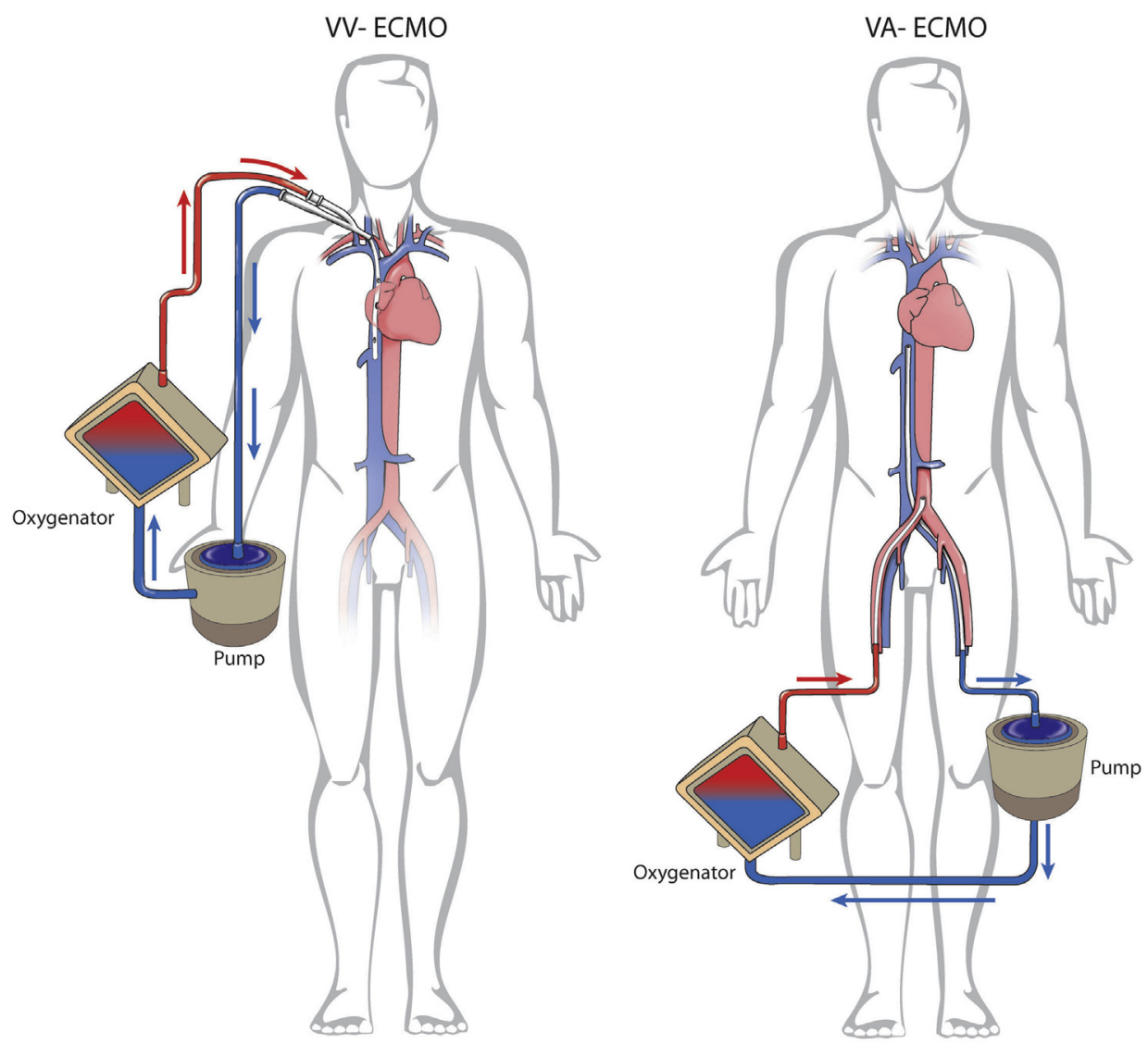

FIGURE 2. Commonly implemented venovenous $(V V)$ (left) and venoarterial (VA) (right) extracorporeal membrane oxygenation $(E C M O)$ circuit cannulation schemes.

Despite the fact that fewer than a third of patients demonstrated clinical improvement and only $5(18 \%)$ were long-term survivors, the authors concluded, "ECMO support is lifesaving in selected cases of pulmonary insufficiency. Initial trials in cardiac failure and the infant age group in this series suggest that ECMO will have an even greater role in those applications." ${ }^{28}$ Herein, we aim to systematically review the contemporary evidence basis for ECMO, 40 years after this initial call for the increased role of ECMO in the treatment of critical cardiac and/or pulmonary failure.

\section{SYSTEMATIC REVIEW}

A systematic review of the evidence basis for ECMO therapy was conducted according to the Preferred Reporting Items for Systematic Reviews and Meta-Analyses guidelines (Figure 3). ${ }^{29}$ We performed a search of the PubMed/MEDLINE database for articles on ECMO therapy from inception to December 1, 2015. All articles with the term extracorporeal membrane oxygenation, $E C M O$, or extracorporeal life support located in the title, abstract, or key words were identified. Results were limited to articles written in the English language and reporting data on adult human subjects. Additionally, references from key manuscripts were manually searched in a backward snowballing fashion for additional articles.

The resulting list of citations, minus duplicates, was screened at the title/abstract level to identify potentially pertinent studies. Articles that reported solely on nonhuman and/or nonadult subjects, were limited to case reports, lacked original data, or focused on topics not covered in this expert review were removed. The full texts of all remaining manuscripts were retrieved for further assessment. Inclusion criteria were study design providing the highest level of evidence for each indication for ECMO (varying from case series to randomized controlled trial, depending on indication $^{30}$ ) (Table 1), cohort studies must include at least 10 patients in the cohort receiving ECMO, and case series must include at least 100 subjects receiving ECMO. Sample-size cutoffs were chosen pre hoc in an attempt to limit the risks of imprecision and publication bias. An increased sample-size cutoff was instituted for case series due to the lower level of evidence provided by these studies. In cases where multiple publications reported overlapping data, only the article with the most encompassing data was included. Qualifying studies for each ECMO indication will be presented in the subsequent sections and summarized in corresponding tables. 


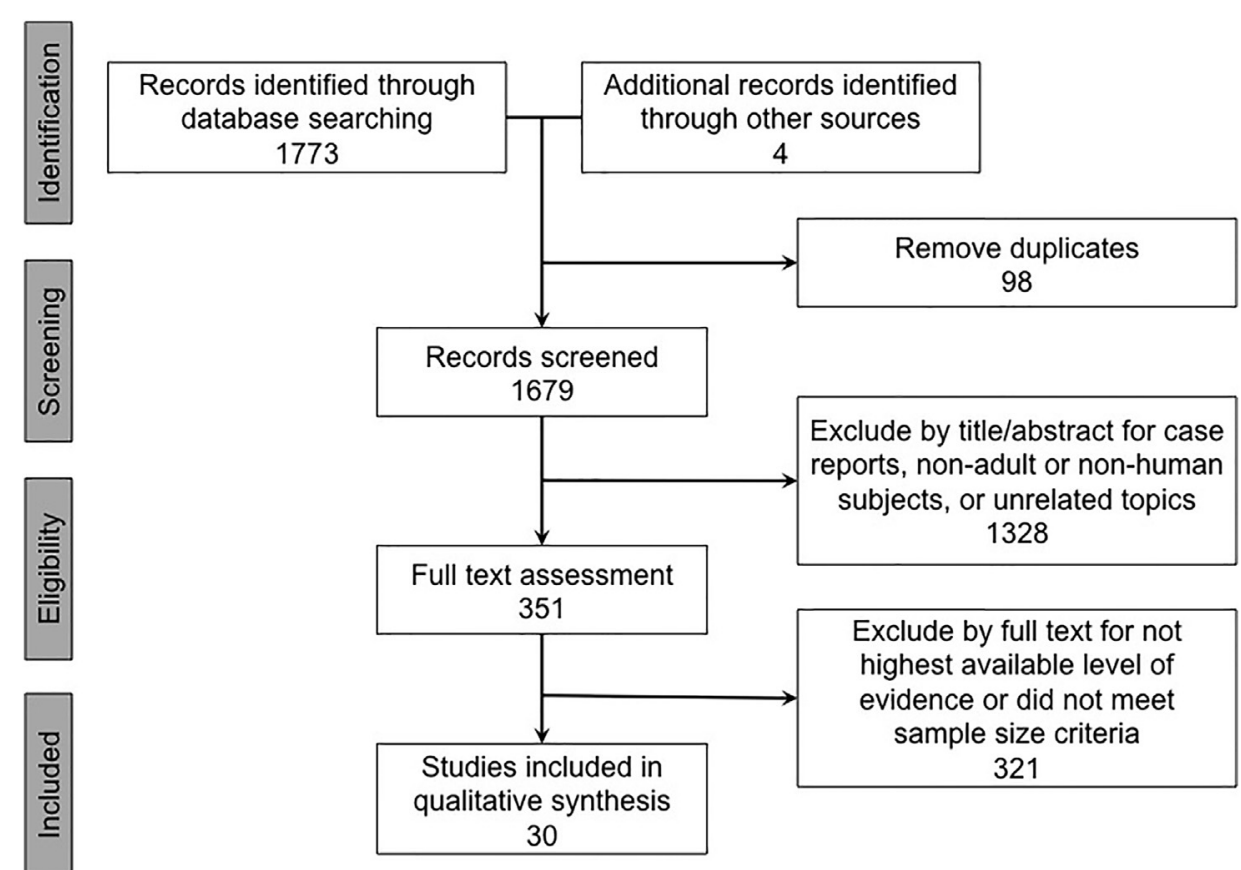

FIGURE 3. Flow diagram of the Preferred Reporting Items for Systematic Reviews and Meta-Analyses (PRISMA) systematic review process.

\section{ECMO APPLICATIONS IN RESPIRATORY \\ FAILURE \\ ECMO for ARDS}

The initial enthusiasm for the life-saving potential of ECMO for ARDS ultimately led to the completion of 3 randomized controlled clinical trials investigating ECMO's performance against conventional therapy (Table 2). ${ }^{7,31,32}$ The first, published in 1979, compared VA ECMO with mechanical ventilation and reported $>90 \%$ mortality for patients in each group. ${ }^{31}$ However, several components of

TABLE 1. Highest level of evidence currently available for a variety of potential indications for extracorporeal membrane oxygenation in both respiratory and cardiac disease

\begin{tabular}{ll}
\hline \multicolumn{1}{c}{ Indication } & Highest level of evidence \\
\hline Respiratory & \\
ARDS & Randomized controlled trials \\
Bridge to lung transplantation & Cohort studies \\
PGD after lung transplantation & Cohort studies \\
Cardiac & \\
MI-associated cardiogenic shock & Historical cohort studies \\
Fulminant myocarditis & Cohort studies \\
Postcardiotomy cardiogenic shock & Case series \\
Extracorporeal cardiopulmonary & Cohort studies with \\
$\quad$ resuscitation & \multicolumn{1}{c}{ propensity analyses } \\
PGD after OHT & Cohort studies \\
Bridge to VAD implantation or OHT & Cohort studies \\
\hline$A R D S$, Acute respiratory distress syndrome; & $P G D$, primary graft dysfunction; \\
$M I$, myocardial infarction; $O H T$, orthotopic heart transplantation; $V A D$, ventricular \\
assist device. Adapted from Abrams and colleagues.
\end{tabular}

the study protocol deviated significantly from modern practice: VA ECMO was implemented instead of VV ECMO, high-pressure high-volume ventilation (mean tidal volume $>13 \mathrm{~mL} / \mathrm{kg}$ body weight) that prevented otherwise beneficial lung rest was inappropriately used, and blood loss in the ECMO group (mean $2.5 \mathrm{~L} / \mathrm{d}$ ) was much higher than would be expected today.

Gattinoni and colleagues ${ }^{33}$ subsequently developed the VV ECMO technique, which allowed for the dissociation of oxygenation (via low-frequency positive-pressure ventilation) from carbon dioxide elimination (via extracorporeal circulation). This strategy facilitated improved lung-protective measures during mechanical ventilation that were lacking in the initial trial. A second randomized trial, composed of only 40 patients and published in 1994, compared the VV ECMO technique against a mechanical ventilation control group. ${ }^{32}$ In that study, mechanical ventilation outperformed ECMO, with 3-month survival limited to $42 \%$ and $33 \%$, respectively. Although an improved ventilator management strategy for patients on ECMO was applied, excessive tidal volumes were maintained (mean tidal volume $>8 \mathrm{~mL} / \mathrm{kg}$ ), and therefore complete lung rest was likely precluded in this trial as well. Excessive blood loss on ECMO (mean $2.7 \mathrm{~L} / \mathrm{d}$ ) was again present, and the study was performed by a center with extremely limited ECMO experience (only 2 humans and 7 sheep) before commencing patient enrollment.

In 2009, the Conventional Ventilator Support versus Extracorporeal Membrane Oxygenation for Severe Adult 
TABLE 2. Summary of randomized controlled trials investigating extracorporeal membrane oxygenation (ECMO) therapy for adult acute respiratory disease syndrome (ARDS)

\begin{tabular}{|c|c|c|c|c|}
\hline Study (y) & $\begin{array}{c}\text { ECMO } \\
\text { (No. patients) }\end{array}$ & $\begin{array}{c}\text { Control } \\
\text { (No. patients) }\end{array}$ & $\begin{array}{c}\text { Outcome } \\
(\% \text { survival } \\
\text { at primary end point }) \\
\end{array}$ & Notes \\
\hline $\begin{array}{l}\text { Zapol and } \\
\text { colleagues (1979) }\end{array}$ & VA ECMO (42) & Mechanical ventilation (48) & $\begin{array}{l}\text { ECMO: } 9.5 \% \\
\text { Control: } 8.3 \%\end{array}$ & $\begin{array}{l}\text { Limitations of ECMO included VA cannulation, } \\
\text { high positive pressure ventilation preventing } \\
\text { lung rest, and excessive blood loss }\end{array}$ \\
\hline $\begin{array}{l}\text { Morris and } \\
\text { colleagues (1994) }\end{array}$ & VV ECMO (21) & Mechanical ventilation (19) & $\begin{array}{l}\text { ECMO: } 33 \% \\
\text { Control: } 42 \%\end{array}$ & $\begin{array}{l}\text { Limitations of ECMO included limited prior } \\
\text { experience at trial center, high positive pressure } \\
\text { ventilation preventing lung rest, and excessive } \\
\text { blood loss }\end{array}$ \\
\hline $\begin{array}{l}\text { Peek and } \\
\text { colleagues (2009) }\end{array}$ & VV ECMO $(68 / 90)^{*}$ & Mechanical ventilation (90) & $\begin{array}{l}\text { ECMO: } 63 \% \\
\text { Control: } 47 \%\end{array}$ & $\begin{array}{l}\text { Intention-to-treat analysis; first RCT allowing } \\
\text { modern lung-protective mechanical ventilation } \\
\text { strategies in study groups (although not required) }\end{array}$ \\
\hline
\end{tabular}
consideration for ECMO actually received ECMO therapy.

Respiratory Failure trial produced results suggesting that modern ECMO may indeed fulfill the expectations of its earliest proponents. This study compared 180 adults randomized to conventional ventilatory support against consideration for VV ECMO, with encouragement for both groups to be placed on modern ventilation protocols that included lung protective measures (tidal volume, 4-8 $\mathrm{mL} / \mathrm{kg}){ }^{7}$ At 6 months of follow-up, patients randomized to consideration for ECMO had superior survival with absence of disability (63\% ECMO vs $47 \%$ conventional therapy; relative risk for mortality or severe disability, $0.69 ; P=.03$ ). This study has its own notable limitations, including that only $75 \%$ of patients randomized to consideration for ECMO actually received this therapy. Moreover, the pragmatic trial design did not mandate a ventilation strategy for the control group, and, although a modern lung-protective strategy was strongly advised, only $70 \%$ of control patients were managed with a lung-protective strategy versus $93 \%$ of patients given consideration for ECMO $(P<.0001)$. Despite the trial's success, these limitations make it difficult to objectively assess the isolated effect of ECMO therapy on survival in patients with ARDS.

A fourth randomized controlled trial investigating the use of ECMO in ARDS is scheduled to complete data collection during early 2016 (https://clinicaltrials.gov/ct2/show/ NCT01470703). The design of the international Extracorporeal Membrane Oxygenation for Severe Acute Respiratory Distress Syndrome trial may clarify the findings of the Conventional Ventilator Support versus Extracorporeal Membrane Oxygenation for Severe Adult Respiratory Failure trial, because patients will be randomized to initiation of VV ECMO versus conventional mechanical ventilation with lung-protective strategies (tidal volume, $6 \mathrm{~mL} / \mathrm{kg}$ ). Results of this investigation are eagerly anticipated.

\section{ECMO and Lung Transplantation}

Although outdated guidelines have listed ECMO as a relative contraindication to lung transplantation, the use of ECMO for bridging patients with end-stage pulmonary failure to lung transplantation has been increasing dramatically: from only 4 patients between 2000 and 2002 to 67 patients in 2009 to 2011 documented in the United Network for Organ Sharing database. ${ }^{34}$ To bridge patients to lung transplantation, clinicians have applied both VV and VA ECMO, depending on patient hemodynamic stability and the presence of pulmonary hypertension.

Four centers have published cohort studies comparing patients bridged to lung transplantation with ECMO with those not requiring mechanical support (Table 3). ${ }^{35-38}$ These reports document attempts to bridge patients for a mean duration of 4 to 14 days with $75 \%$ to $90 \%$ of patients successfully bridged to transplantation and 1-year posttransplant survival between $60 \%$ and $93 \%$. Two of the studies demonstrated noninferior survival in the ECMO-bridged group. ${ }^{35,38}$ A third study reported lower overall survival in bridged patients at 1,3 , and 5 years but no significant differences at these intervals after analysis conditioned upon initial 3-month survival. ${ }^{36}$ The final study compared ECMO-bridged patients with other high-acuity patients who did not receive mechanical support. ${ }^{37}$ Although overall survival was inferior in the ECMObridged group, 1-year survival in the ECMO group was exceptional $(93 \%)$. Taken together, these results suggest that ECMO-bridged transplant recipients may be subject to an increased risk for early morbidity and mortality, but can be successfully transplanted with excellent results, especially considering the likely $100 \%$ mortality for such patients without the option for ECMO-bridging.

ECMO has also been used for patient support after lung transplantation, particularly in patients with severe primary 
TABLE 3. Cohort studies reporting the 1-year survival outcomes of extracorporeal membrane oxygenation (ECMO) therapy for bridge to lung transplantation in adults

\begin{tabular}{|c|c|c|c|c|c|c|}
\hline \multirow[b]{2}{*}{ Study (y) } & \multirow[b]{2}{*}{$\begin{array}{l}\text { ECMO support } \\
\text { (No. patients) }\end{array}$} & \multirow{2}{*}{$\begin{array}{c}\text { Successfully } \\
\text { ECMO-bridged } \\
\text { (No. patients [\%]) }\end{array}$} & \multirow[b]{2}{*}{$\begin{array}{l}\text { Mean bridging } \\
\text { time (d) }\end{array}$} & \multicolumn{2}{|c|}{ 1-y Survival } & \multirow[b]{2}{*}{$P$ value } \\
\hline & & & & $\begin{array}{c}\text { Bridged recipients } \\
(\%)\end{array}$ & $\begin{array}{c}\text { Nonbridged recipients } \\
(\%)\end{array}$ & \\
\hline Shafii and colleagues (2012) & 19 & $14(74)$ & 6.0 & 75 & $\mathrm{NR}^{*}$ & .98 \\
\hline Lang and colleagues (2012) & 38 & $34(89)$ & 4.5 & 60 & 72 & .028 \\
\hline Hoopes and colleagues (2013) & 35 & $31(87)$ & 13.7 & 93 & $\mathrm{NR} \dagger$ & $<.001$ \\
\hline Toyoda and colleagues (2013) & 31 & $24(77)$ & 7.1 & 74 & 83 & .787 \\
\hline
\end{tabular}

ECMO, Extracorporeal membrane oxygenation; $N R$, not reported. *Specific survival rate not reported for nonbridged group, but Kaplan-Meier survival analysis performed for comparison demonstrated no significant difference. $†$ Specific survival rate not reported for nonbridged group, but Kaplan-Meier survival analysis performed for comparison demonstrated a significantly higher survival rate in the nonbridged group.

graft dysfunction (PGD). ${ }^{39-44}$ Patients requiring ECMO support for severe PGD have inferior survival compared with patients without PGD, but these patients' outcomes have matched those of patients with less severe PGD not requiring ECMO. Both VA and VV ECMO have been used to allow for recovery of the lung allograft, but $\mathrm{VV}$ ECMO is now favored after Hartwig and colleagues ${ }^{40}$ demonstrated significantly better results using this cannulation strategy (30-day survival, VA $13 \%$ vs VV $88 \%$ ). The improved outcomes with VV ECMO were most likely due to the lower frequencies of devastating neurological complications and sepsis with this strategy. Subsequently, Hartwig and colleagues ${ }^{44}$ have described patient outcomes after designating VV ECMO as the standard modality of treatment at their center, with 30-day survival of $82 \%$ in the ECMO group versus $97 \%$ in the non-ECMO group. Despite the impressive rate of survival after ECMO support, maximum allograft function in ECMO recipients was considerably diminished as compared to non-ECMO recipients at 3 years (peak forced expiratory volume in 1 second, ECMO 58\% vs non-ECMO $83 \% ; P=.001)$.

\section{ECMO APPLICATIONS IN CARDIAC FAILURE ECMO for Cardiogenic Shock}

Cardiogenic shock has a variety of etiologies, including postcardiotomy shock, fulminant myocarditis, and shock secondary to acute myocardial infarction. ECMO and other mechanical circulatory support systems may offer an advantage over conventional medical therapy for cardiogenic shock. ${ }^{30}$ Medical agents, including inotropes and vasopressors, improve cardiac output through mechanisms that increase myocardial oxygen use and increase risk for myocardial ischemia, cardiac arrhythmias, and tissue hypoperfusion. Mechanical support systems, on the other hand, increase cardiac output without placing additional demands on myocardial tissue. ECMO, in particular, offers unique advantages such rapid insertion times, biventricular support, and ability to allow for lung rest in cases of concomitant pulmonary failure. ${ }^{30}$ Cohort studies investigating the outcomes of patients treated with
VA ECMO for cardiogenic chock in several well-studied etiologies are summarized in Table 4.

A variety of studies have attempted to isolate cardiogenic shock resulting from individual etiologies to determine the effectiveness of ECMO salvage in each disease. For patients experiencing profound cardiogenic shock secondary to acute myocardial infarction, the availability of ECMO therapy appeared to offer a survival advantage in 2 historical cohort studies. ${ }^{45,46}$ Both studies compared survival in a more recent era in which ECMO therapy was available against distant eras without the option for ECMO, so a potential bias may have been introduced into these studies based on other care improvements available only in the modern eras. Another factor limiting the isolation of the true efficacy of ECMO therapy is that, in the modern cohorts, not all patients actually received ECMO $(21 \%$ and $55 \%$, respectively, were placed on ECMO). Nevertheless, in cases of profound cardiogenic shock-complicated acute myocardial infarction, the availability of ECMO to salvage patients before or during percutaneous coronary intervention appears to improve short-term survival, with approximately $70 \%$ of patients surviving to 30 days.

Similarly, ECMO has been applied to rescue patients with cardiogenic shock of a nonischemic etiology, including fulminant myocarditis. ${ }^{47}$ In a study with relatively small cohorts, patients with fulminant myocarditis, defined as those patients without sufficient response to maximum medical therapy for acute myocarditis, achieved a successful wean rate of $71 \%$, with all weaned patients surviving long-term (median follow-up, 50 months).

ECMO has also been increasingly used to support patients suffering postcardiotomy shock (PCS). Given the certain mortality of patients with PCS not offered ECMO salvage, only case series are currently available to assess the effectiveness of ECMO for PCS, 4 of which report outcomes in at least 100 patients. ${ }^{48-51}$ Although survival remains relatively scarce in these case series $(25 \%-42 \%)$, VA ECMO clearly offers an advantage to patients and surgeons who have virtually no other alternative in the rare instances of PCS. An encouraging finding that has been replicated in 
TABLE 4. Cohort studies and case studies reporting the outcomes of extracorporeal membrane oxygenation (ECMO) therapy for cardiogenic shock

\begin{tabular}{|c|c|c|c|c|c|c|}
\hline \multirow[b]{2}{*}{ Study $(\mathbf{y})$} & \multirow[b]{2}{*}{$\begin{array}{c}\text { Etiology } \\
\text { (duration) }\end{array}$} & \multirow[b]{2}{*}{$\begin{array}{l}\text { ECMO group } \\
\text { (No. patients) }\end{array}$} & \multirow[b]{2}{*}{$\begin{array}{l}\text { Control group } \\
\text { (No. patients) }\end{array}$} & \multicolumn{2}{|c|}{ Primary survival analysis } & \multirow[b]{2}{*}{$P$ value } \\
\hline & & & & ECMO group (\%) & $\begin{array}{c}\text { Control group } \\
(\%)\end{array}$ & \\
\hline Sheu and colleagues (2010) & AMI (30 d) & $115^{*}$ & 219 & 70 & 58 & .04 \\
\hline Tsao and colleagues (2012) & AMI (30 d) & $33^{*}$ & 25 & 67 & 32 & .001 \\
\hline Asaumi and colleagues (2005) & FM (acute period) & 14 & $13 \dagger$ & 71 & 100 & NR \\
\hline Elsharkawy and colleagues (2010) & PCS (to discharge) & 233 & - & 36 & - & - \\
\hline Wu and colleagues (2010) & PCS (to discharge) & 110 & - & 42 & - & - \\
\hline Rastan and colleagues (2010) & PCS (to discharge) & 517 & - & 25 & - & - \\
\hline Park and colleagues (2014) & PCS (to discharge) & 115 & - & 28 & - & - \\
\hline
\end{tabular}

ECMO, Extracorporeal membrane oxygenation; $A M I$, acute myocardial infarction; $F M$, fulminant myocarditis; $N R$, not reported; $P C S$, postcardiotomy shock. *In cardiogenic shock-AMI studies, ECMO group consisted of patient cohorts for whom ECMO was available, although not all patients in the cohort were placed on ECMO. Control group was a historical cohort for whom ECMO was not available. $\dagger$ Control group in this FM study was patients classified with non-FM; that is, those patients who responded to conventional medical therapy without the need for mechanical support.

several studies is excellent long-term survival in patients surviving the acute perioperative period. Only sparse data are available to suggest which patients are most likely to survive ECMO salvage for PCS, but recent investigations have identified serial blood lactate measurements in the acute 24-hour period following initiation of ECMO as a simple, reliable tool to monitor for inadequate tissue perfusion, which appears to be a strong marker of mortality. ${ }^{51}$

\section{ECMO and Cardiac Transplantation}

In a manner similar to lung transplantation, ECMO has been applied to bridge patients to orthotopic heart transplantation and to support patients with PGD posttransplantation. A pair of key studies have investigated optimal bridging pathways for patients requiring cardiac transplantation and/or LVAD support. ${ }^{52,53}$ In the first, patients with refractory cardiogenic shock were treated using mechanical assistance with intent to bridge to transplantation. $^{52}$ Those with cardiac arrest or severe hemodynamic instability with evidence of multiorgan failure were initially placed on ECMO $(\mathrm{n}=14)$, and the others with less severe status $(n=18)$ were immediately implanted with LVADs. Of the patients on ECMO, a total of $7(50 \%)$ eventually received LVADs and 1 was directly transplanted. Ultimately, 5 of the ECMO-to-LVAD patients were transplanted, and all 6 ECMO patients receiving transplantation survived to hospital discharge. Of the patients surviving ECMO-to-LVAD or ECMO-to-transplant, 1-year survival $(71 \%)$ was no different than the group directly implanted with LVADs $(75 \%)$. These results suggest that ECMO resuscitation is an effective, resourcesensitive strategy to salvage patients in extremis, rather than the immediate implantation of a LVAD, which can instead be offered following a period of ECMO support with no impact on subsequent survival.

More recently, an analysis of the United Network for Organ Sharing database from 2000 to 2010 determined that isolated ECMO-bridging of patients increased the risk of death following transplantation (hazard ratio, 2.2 vs no mechanical support; $P<.001$ ), but that patients initially supported with ECMO who were transitioned to LVAD-only support had comparable posttransplantation survival to patients who had LVAD-only support from the time of listing. ${ }^{53}$ Considering these 2 key studies together, the appropriate role for ECMO in bridging to cardiac transplantation appears to be in the initial resuscitation of patients before implantation of LVAD devices in eligible candidates.

ECMO has also been used for patient support following heart transplantation in cases of PGD (Table 5). ${ }^{54-56}$ Not surprisingly, patients requiring ECMO support for PGD have decreased 30-day survival compared with patients without PGD and not requiring support. However, in each of the available studies comparing these groups, conditioned survival analyses have determined that patients with PGD supported by ECMO who survive beyond the acute posttransplantation period have equivalent survival to non-ECMO patients. Landmark analyses performed as early as 30 days postoperatively demonstrate survival equivalence in the ECMO salvage groups, suggesting that early ECMO support may not have long-term consequences on cardiac graft function if the supported patient survives salvage therapy.

\section{ECMO for Cardiopulmonary Resuscitation}

Finally, the use of ECMO for cardiopulmonary resuscitation (E-CPR) after cardiac arrest has been increasing in recent years. Several Asian centers have reported superior outcomes in patients treated with E-CPR compared with conventional CPR (C-CPR) in both inpatient ${ }^{57-59}$ and out-of-hospital settings (Table 6) ${ }^{60,61}$ Despite the improved survival in the ECPR cohorts, survival remains relatively low, with out-ofhospital arrests (15\%-28\% survival at 3 months) not surprisingly experiencing decreased survival rates compared with 
TABLE 5. Cohort studies reporting the outcomes of patients treated with extracorporeal membrane oxygenation (ECMO) for primary graft dysfunction following orthotopic heart transplantation

\begin{tabular}{|c|c|c|c|c|c|}
\hline \multirow[b]{2}{*}{ Study (y) } & \multirow[b]{2}{*}{$\begin{array}{l}\text { ECMO group } \\
\text { (No. patients) } \\
\end{array}$} & \multirow[b]{2}{*}{$\begin{array}{c}\text { Comparison group } \\
\text { (No. patients) }\end{array}$} & \multicolumn{2}{|c|}{ 30-D or to-discharge survival } & \multirow[b]{2}{*}{$P$ value } \\
\hline & & & $\begin{array}{c}\text { ECMO group } \\
(\%) \\
\end{array}$ & $\begin{array}{c}\text { Control group } \\
(\%) \\
\end{array}$ & \\
\hline D'Alessandro and colleagues (2010) & 54 & 304 & 50 & 87 & NR \\
\hline Marasco and colleagues (2010) & 39 & 185 & 74 & $\mathrm{NR}^{*}$ & .007 \\
\hline Listijono and colleagues (2011) & 17 & 107 & 82 & 100 & $<.001$ \\
\hline
\end{tabular}

$E C M O$, Extracorporeal membrane oxygenation; $N R$, not reported. *Specific survival rate not reported in the control group, but Kaplan-Meier survival analysis performed for comparison demonstrated a significantly higher survival rate in the control group.

in-hospital arrests ( $29 \%-31 \%$ at 6 months). Survival benefits of E-CPR appear to extend several years beyond the acute cardiac arrest. ${ }^{58}$ A secondary advantage of E-CPR is a demonstrated trend toward improved long-term neurologic status in successfully resuscitated patients. Despite the success of E-CPR compared with C-CPR, the low survival rates reported in these studies suggests that further research is necessary to determine which patients are likely to benefit from E-CPR. Limited data on predictive factors are currently available, but reported variables include younger age, $\mathrm{C}$-CPR duration $<35$ minutes before initiation of E-CPR, pupil size on arrival to the hospital, and subsequent coronary intervention. ${ }^{59,60}$ The recently updated American Heart Association guidelines on CPR reflect both the rise of E-CPR as a viable option in cardiac arrest and the importance of proper patient selection for E-CPR, stating that candidates should have a suspected etiology of arrest that is reversible during a short period of ECMO support. ${ }^{62}$

\section{COMPLICATIONS}

Technologic improvements have recently led to the development of portable, self-contained, miniaturized ECMO systems that may reduce the incidence of certain complications. ${ }^{63,64}$ These devices represent an improvement in traditional homemade ECMO circuits for a variety of reasons. Most importantly, the systems have undergone design verification and validation by their manufacturers, which reduces risk for circuit-related complications and informs routine circuit monitoring. The component integration of the systems also increases ease of use and allows for rapid deployment within 15 minutes. System portability facilitates patient transfer within the same hospital, to the computed tomography scanner for instance, or even from 1 care facility to another. ${ }^{65}$

Nevertheless, given the complexity of ECMO therapy and the severity of patient pathology, the high risk for complications, even with modern ECMO, is not surprising. Complications can arise from patient factors or malfunctions of ECMO circuit components. Regular monitoring and testing is essential to identify complications or potential complications early so that they can be addressed rapidly or avoided altogether.
Two critical circuit complications may require the immediate clamping and discontinuation of ECMO to facilitate resolution: gas embolism and massive blood loss secondary to tubing ruptures or disconnections. Gas emboli are a risk particularly with centrifugal pumps because these units generate a negative pressure between the drainage cannula and the pump head. If negative pressures become too extreme, air entrapment in this section of the circuit may result in massive gas embolism. Gas emboli occur in $<2 \%$ of ECMO runs in adults. ${ }^{66}$

Other ECMO circuit complications include blood clots, loss of circuit flow (usually secondary to hypovolemia), and primary failure of circuit components. Very limited data are available regarding how often these technical complications occur in modern units. Lubnow and colleagues ${ }^{67}$ recently published an analysis of technical complications occurring in a series of 265 ARDS patients treated with modern miniaturized VV ECMO units. The authors determined that $83(31 \%)$ patients required at least one system exchange due to technical complications with the ECMO circuit. In $45 \%$ of these cases, the exchange was required on an acute, rather than elective, basis. The most common technical complications were progressive clot formation $(50.6 \%)$, acute clot formation $(34.9 \%)$, and primary mechanical failures $(9.6 \%)$, among others. No instances of gas emboli or tubing rupture were reported. Three patients did require bridging by handcrank, all in cases of pump drive failure. ECMO circuits should be equipped with a back-up battery or hand crank in the case of power or mechanical failures. Although modern ECMO units have reduced the incidence of mechanical failures in VA ECMO applications, technical complications remain frequent in this cannulation strategy, as well. ${ }^{68}$

Even with a properly functioning circuit, patients are subject to a wide variety of complications while on ECMO support. Patients are particularly susceptible to bleeding (at the insertion site, surgical site, intracranially, or intra-abdominally) due to required anticoagulation therapy as well as thrombocytopenia and clotting factor deficiencies that are common while on ECMO. Platelets, leukocytes, and clotting factors are activated and consumed 
TABLE 6. Cohort studies with propensity analyses reporting the outcomes of patients treated with extracorporeal membrane oxygenation (ECMO) for extracorporeal cardiopulmonary resuscitation (E-CPR)

\begin{tabular}{|c|c|c|c|c|c|c|}
\hline \multirow[b]{2}{*}{ Study (y) } & \multirow[b]{2}{*}{ Setting (duration) } & \multirow[b]{2}{*}{$\begin{array}{l}\text { E-CPR group } \\
\text { (No. patients) }\end{array}$} & \multirow[b]{2}{*}{$\begin{array}{l}\text { C-CPR group } \\
\text { (No. patients) }\end{array}$} & \multicolumn{2}{|c|}{ Primary survival analysis } & \multirow[b]{2}{*}{$P$ value } \\
\hline & & & & $\begin{array}{c}\text { ECMO group } \\
(\%)\end{array}$ & $\begin{array}{c}\text { Control group } \\
(\%)\end{array}$ & \\
\hline Chen and colleagues (2008) & In hospital (to discharge) & 59 & 113 & 28.8 & 12.3 & $<.0001$ \\
\hline Shin and colleagues $(2011,2013)$ & In hospital (to discharge) & 85 & 321 & 34.1 & 12.1 & $<.001$ \\
\hline Maekawa and colleagues (2013) & Out of hospital (to 3-mo) & 53 & 109 & 28.3 & 4.6 & $<.0001$ \\
\hline Kim and colleagues (2014) & Out of hospital (to 3-mo) & 55 & 444 & 14.5 & 9.9 & $.346^{*}$ \\
\hline
\end{tabular}

when blood contacts the foreign material in the ECMO tubing. Therefore, the majority of patients on ECMO are thrombocytopenic and at risk for bleeding complications.

The reported rates of adverse bleeding events vary between series, often depending on the particular definitions applied in a given report. A meta-analysis on the frequency of a variety of reported complications in 20 studies on more than 1800 patients treated with VA ECMO for cardiogenic shock or cardiac arrest identified 5 studies reporting serious bleeding events and surmised that such events occur in $40.8 \%$ of patients $(95 \%$ confidence interval [CI], $26.8 \%-56.6 \%) .{ }^{69}$ Each of the 5 studies defined and labeled the complication of serious bleeding differently ("major bleeding," "massive bleeding," "severe bleeding," "bleeding and hematoma," and "bleeding and tamponade"), an interesting anomaly that highlights the variability in reporting of ECMO complications. A recently published analysis from a large series of all-comer ECMO patients at a single-center found that $56 \%$ of patient experienced a serious bleeding event, with a rate of bleeding at 10 events per 100 days of ECMO therapy and a trend toward decreased 90-day survival in patients who bled (46.7\% vs $64.9 \%$, respectively; $P=.08) .{ }^{70}$ In this cohort, major bleeding events were more common in VA patients $(68.5 \% ; 19$ events per 100 days) than the VV group ( $39.1 \% ; 6$ events per 100 days).

ECMO is complicated by events in a variety of other systems, including the renal, musculoskeletal, and immune systems. As with bleeding events, the rates of complications in these systems tend to vary between reports and by whether VA or VV ECMO is implemented. The above-mentioned meta-analysis of VA ECMO reported high rates of acute kidney injury $(55.6 \%$; 95\% CI, 35.5\%-74.0\%) and requirement for renal replacement therapy $(46 \% ; 95 \% \mathrm{CI}$, $36.7 \%-55.5 \%$ ). ${ }^{69}$ Lower extremity ischemia, need for lower extremity fasciotomy, and systemic infections also complicated many of the ECMO runs. Despite the large number of patients included in the meta-analysis, the tremendous variability in both of which complications were reported and how each was defined limits the generalizability of the study's findings, as is indicated by the dramatic $95 \%$ CIs reported by the authors.

Neurologic complications during ECMO are particularly devastating. The most common neurologic complications include intracerebral hemorrhage, ischemic stroke, and seizures. Intracerebral hemorrhage, typically a fatal complication, is a significant risk due to the challenge of balancing adequate systemic anticoagulation therapy with the thrombocytopenia manifested in the majority of ECMO patients. Assessing a patient's neurological status can be difficult due to the sedatives and paralytics often prescribed during ECMO. Therefore computed tomography and electroencephalography serve as useful tools to assess for intracranial bleeds and neurologic activity, respectively. ${ }^{71}$

The lack of informative data on ECMO complications and the high degree of variability in the data that are available derives from the fact that clinicians predominantly rely on retrospective, observational studies to determine the incidence of these events. Moreover, the diverse array of indications for ECMO adds to the variable manifestation of complications from one series to the next. Given the challenges in accounting for complications and the inconsistencies in definitions applied to categorize them in the present literature, a standardized method by which to document and classify ECMO complications would likely improve the utility of ECMO reports in the future. By standardizing the definitions of ECMO complications, similar to the way in which end point definitions have been clearly defined for transcatheter aortic valve replacement, ${ }^{72}$ a better understanding of the risks of ECMO could be established.

\section{WEANING FROM ECMO}

Weaning patients from ECMO support, if properly managed, is somewhat simplified because the pump should constantly be generating the minimal flow necessary to provide adequate support at low ventilator settings and inotrope doses. Thus, ECMO support should naturally be 
reduced as native organ function improves. The earliest sign of cardiac recovery in patients on VA ECMO is the return of pulsatility on the arterial waveform. Cardiac function and hemodynamic parameters can also be continually assessed with transesophageal echocardiography during weaning. ${ }^{73}$ A variety of metrics are available to determine if patients on VV ECMO are recovering pulmonary function: an increase in oxygen saturation at a constant circuit flow; a progressive increase of oxygen saturation above venous oxygen saturation, improving lung compliance, and clinical improvements in chest radiography.

ECMO should be continued only if reasonable hope remains for survival in a condition that is acceptable to the patient and/or their family. Therefore, frequent and honest communication with the patient's family members is essential throughout the duration of ECMO therapy. A reasonable deadline for organ recovery or replacement should be set early in the course of ECMO so that decisions regarding futility can be made with as much objectivity as is possible. The majority of patients successfully weaned from VA ECMO for cardiac failure after 2 to 5 days of support. ${ }^{50}$ Recovery of pulmonary function on VV ECMO typically takes longer, with 1 to 3 weeks the most frequently reported interval of success. ${ }^{74}$ However, recently published, limited evidence suggests that modern VV ECMO support beyond 3 weeks may effectively allow bridging of patients to recovery or transplantation in select cases. ${ }^{75}$ Successful bridge to transplantation after VV ECMO therapy has been reported as many as 155 days after initiation of support, ${ }^{76}$ and successful weaning to complete recovery has been reported as many as 117 days after initiation of ECMO. ${ }^{77}$

\section{CONCLUSIONS}

ECMO provides days to weeks of support to patients with respiratory, cardiac, or combined cardiopulmonary failure. The indications for and implementations of ECMO have continued to diversify during the past decade due to a variety of factors that have promoted its utility. ECMO will increasingly become available to a wide population of critically ill patients in the coming years. Therefore, it is essential for clinicians to be familiar with the contemporary evidence basis and management of ECMO therapy.

\section{Conflicts of Interest Statement}

Authors have nothing to disclose with regard to commercial support.

The authors thank Kristin Yang for her excellent figure illustrations and Leah Gaither for her editorial assistance.

\section{References}

1. Extracorporeal Life Support Registry report (international summary). Ann Arbor: Extracorporeal Life Support Organization; 2015.

2. Sauer CM, Yuh DD, Bonde P. Extracorporeal membrane oxygenation use has increased by $433 \%$ in adults in the United States from 2006 to 2011. ASAIO J. 2015;61:31-6.
3. Maxwell BG, Powers AJ, Sheikh AY, Lee PH, Lobato RL, Wong JK. Resource use trends in extracorporeal membrane oxygenation in adults: an analysis of the Nationwhide Inpatient Sample 1998-2009. J Thorac Cardiovasc Surg. 2014;148:416-21.

4. The Australia and New Zealand Extracorporeal Membrane Oxygenation (ANZ ECMO) Influenza Investigators, Davies A, Jones D, Bailey M, Beca J, Bellomo R, Blackwell N, et al. Extracorporeal membrane oxygenation for 2009 influenza A (H1N1) acute respiratory distress syndrome. JAMA. 2009; 302:1888-95.

5. Bermudez CA, Rocha RV, Sappington PL, Toyoda Y, Murray HN, Boujoukos AJ Initial experience with single cannulation for venovenous extracorporeal oxygenation in adults. Ann Thorac Surg. 2010;90:991-5.

6. Bryner B, Cooley E, Copenhaver W, Brierley K, Teman N, Landis D, et al. Two decades' experience with interfacility transport on extracorporeal membrane oxygenation. Ann Thorac Surg. 2014;98:1363-70.

7. Peek GJ, Mugford M, Tiruvoipati R, Wilson A, Allen E, Thalanany MM, et al. Efficacy and economic assessment of conventional ventilatory support versus extracorporeal membrane oxygenation for severe adult respiratory failure (CESAR): a multicentre randomised controlled trial. Lancet. 2009;374: 1351-63.

8. Bartlett RH, Gattinoni L. Current status of extracorporeal life support (ECMO) for cardiopulmonary failure. Minerva Anestesiol. 2010;76:534-40.

9. Chamogeorgakis T, Lima B, Shafii AE, Nagpal D, Pokersnik JA, Navia JL, et al. Outcomes of axillary artery side graft cannulation for extracorporeal membrane oxygenation. J Thorac Cardiovasc Surg. 2013;145:1088-92.

10. Vallabhajosyula P, Kramer M, Lazar S, McCarthy F, Rame E, Wald J, et al. Lower extremity complications with femoral extracorporeal life support. J Thorac Cardiovasc Surg. 2016;151:1738-44.

11. Black MC, Slaughter MS. Proactive or reactive? Best approach to limb ischemia in peripheral venoarterial extracorporeal life support. J Thorac Cardiovasc Surg. 2016;151:1745-6.

12. Aiyagari RM, Rocchini AP, Temenapp RT, Graziano JN. Decompression of the left atrium during extracorporeal membrane oxygenation using a transseptal cannula incorporated into the circuit. Crit Care Med. 2006;34:2603-6.

13. Koeckert MS, Jourde UP, Naka Y, Moses JW, Takayama H, Impella LP. 2.5 for left ventricular unloading during venoarterial extracorporeal membrane oxygenation support. J Card Surg. 2011;26:666-8.

14. Cheng A, Swartz MF, Todd MH. Impella to unload the left ventricle during peripheral extracorporeal membrane oxygenation. ASAIO J. 2013;59:533-6.

15. Samuels L, Gnall E, Casanova-Ghosh E, Plestis K. A hybrid configuration of a left ventricular assist device and venovenous extracorporeal membrane oxygenation. J Thorac Cardiovasc Surg. 2016;151:e75-6.

16. Magovern GJ. More than one way to skin a cat. J Thorac Cardiovasc Surg. 2016; 151:e77-8.

17. Chung M, Shiloh AL, Carlese A. Monitoring of the adult patient on venoarterial extracorporeal membrane oxygenation. Scientific World J. 2014;2014:393258.

18. Rich PB, Awad SS, Crotti S, Hirschl RB, Bartlett RH, Schreiner RJ. A prospective comparison of atrio-femoral and femoro-atrial flow in adult venovenous extracorporeal life support. J Thorac Cardiovasc Surg. 1998;116:628-32.

19. Khoshbin E, Roberts N, Harvey C, Machin D, Killer H, Peek GJ, et al. Poly-methyl pentene oxygenators have improved gas exchange capability and reduced transfusion requirements in adult extracorporeal membrane oxygenation. ASAIO J. 2005;51:281-7.

20. Toomasian JM, Bartlett RH. Hemolysis and ECMO pumps in the 21st century. Perfusion. 2011;26:5-6.

21. Halaweish I, Cole A, Cooley E, Lynch WR, Haft JW. Roller and centrifugal pumps: a retrospective comparison of bleeding complications in extracorporeal membrane oxygenation. ASAIO J. 2015;61:496-501.

22. von Frey M, Gruber M. Untersuchungen uber den Stoffwechsel isolirter Organe. I. Ein Respirationsapparat fur isolirte Organe. Arch Anat Physiol. 1885;519-32.

23. Gibbon JH. Application of a mechanical heart and lung apparatus to cardiac surgery. Minn Med. 1954;37:171-80.

24. Lee WH Jr, Krumhar D, Fonkalsrud EW, Schjeide OA, Maloney JV Jr. Denaturation of plasma proteins as a cause of morbidity and death after intracardiac operations. Surgery. 1961;50:29-39.

25. Clowes GH Jr, Hopkins AL, Neville WE. An artificial lung dependent upon diffusion of oxygen and carbon dioxide through plastic membranes. J Thorac Surg. 1956;32:630-7.

26. Bramson ML, Osborn JJ, Main FB, O’Brien MF, Wright JS, Gerbode F. A new disposable membrane oxygenator with integral heat exchanger. J Thorac Cardiovasc Surg. 1965;50:391-400. 
27. Hill JD, O’Brien TG, Murray JJ, Dontigny L, Bramson ML, Osborn JJ, et al. Prolonged extracorporeal oxygenation for acute post-traumatic respiratory failure (shock-lung syndrome)—use of the Bramson membrane lung. $N$ Engl J Med. 1972;286:629-34.

28. Bartlett RH, Gazzaniga AB, Fong SW, Jefferies MR, Roohk HV, Haiduc N. Extracorporeal membrane oxygenator support for cardiopulmonary failure. Experience in 28 cases. J Thorac Cardiovasc Surg. 1977;73:375-86.

29. Shamseer L, Moher D, Clarke M, Ghersi D, Liberati A, Petticrew M, et al. Preferred reporting items for systematic review and meta-analysis protocols (PRISMA-P) 2015: elaboration and explanation. BMJ. 2015; 349:g7647.

30. Abrams D, Combes A, Brodie D. Extracorporeal membrane oxygenation in cardiopulmonary disease in adults. J Am Coll Cardiol. 2014;63:2769-78.

31. Zapol WM, Snider MT, Hill JD, Fallat RJ, Bartlett RH, Edmunds LH, et al. Extracorporeal membrane oxygenation in severe acute respiratory failure: A randomized prospective study. JAMA. 1979;242:2193-6.

32. Morris AH, Wallace CJ, Menlove RL, Clemmer TP, Orme JF Jr, Weaver LK, et al. Randomized clinical trial of pressure-controlled inverse ratio ventilation and extracorporeal $\mathrm{CO} 2$ removal for adult respiratory distress syndrome. Am J Respir Crit Care Med. 1994;149:295-305.

33. Gattinoni L, Agostoni A, Pesenti A, Pelizzola A, Rossi GP, Langer M, et al. Treatment of acute respiratory failure with low-frequency positive-pressure ventilation and extracorporeal removal of CO2. Lancet. 1980;2:292-4.

34. Hayanga AJ, Aboagye J, Esper S, Shigemura N, Bermudez CA, D'Cunha J, et al. Extracorporeal membrane oxygenation as a bridge to lung transplantation in the United States: an evolving strategy in the management of rapidly advancing pulmonary disease. J Thorac Cardiovasc Surg. 2015;149:291-6.

35. Shafii AE, Mason DP, Brown CR, Vakil N, Johnston DR, McCurry KR, et al. Growing experience with extracorporeal membrane oxygenation as a bridge to lung transplantation. ASAIO J. 2012;58:526-9.

36. Lang G, Taghavi S, Aigner C, Renyi-Vamos F, Jaksch P, Augustin V, et al. Primary lung transplantation after bridge with extracorporeal membrane oxygenation: a plea for a shift in our paradigms for indications. Transplantation. 2012;93:729-36.

37. Hoopes CW, Kukreja J, Golden J, Davenport DL, Diaz-Guzman E, Zwischenberger JB. Extracorporeal membrane oxygenation as a bridge to pulmonary transplantation. J Thorac Cardiovasc Surg. 2013;145:862-8.

38. Toyoda Y, Bhama JK, Shigemura N, Zaldonis D, Pilewski J, Crespo M, et al. Efficacy of extracorporeal membrane oxygenation as a bridge to lung transplantation. J Thorac Cardiovasc Surg. 2013;145:1065-71.

39. Dahlberg PS, Prekker ME, Herrington CS, Hertz MI, Park SJ. Medium-term results of extracorporeal membrane oxygenation for severe acute lung injury after lung transplantation. J Heart Lung Transplant. 2004;23:979-84.

40. Hartwig MG, Appel JZ III, Cantu E III, Simsir S, Lin SS, Hsieh CC, et al. Improved results treating lung allograft failure with venovenous extracorporeal membrane oxygenation. Ann Thorac Surg. 2005;80:1872-80.

41. Mason DP, Boffa DJ, Murthy SC, Gildea TR, Budev MM, Mehta AC, et al. Extended use of extracorporeal membrane oxygenation after lung transplantation. J Thorac Cardiovasc Surg. 2006;132:954-60.

42. Wigfield CH, Lindsey JD, Steffens TG, Edwards NM, Love RB. Early institution of extracorporeal membrane oxygenation for primary graft dysfunction after lung transplantation improves outcome. J Heart Lung Transplant. 2007:26:331-8

43. Bermudez CA, Adusumilli PS, McCurry KR, Zaldonis D, Crespo MM, Pilewski JM, et al. Extracorporeal membrane oxygenation for primary graft dysfunction after lung transplantation: long-term survival. Ann Thorac Surg. 2009;87:854-60.

44. Hartwig MG, Walczak R, Lin SS, Davis RD. Improved survival but marginal allograft function in patients treated with extracorporeal membrane oxygenation after lung transplantation. Ann Thorac Surg. 2012;93:366-71.

45. Sheu JJ, Tsai TH, Lee FY, Fang HY, Sun CK, Leu S, et al. Early extracorporeal membrane oxygenator-assisted primary percutaneous coronary intervention improved 30-day clinical outcomes in patients with ST-segment elevation myocardial infarction complicated with profound cardiogenic shock. Crit Care Med. 2010;38:1810-7.

46. Tsao NW, Shih CM, Yeh JS, Kao YT, Hsieh MH, Ou KL, et al. Extracorporeal membrane oxygenation — assisted primary percutaneous coronary intervention may improve survival of patients with acute myocardial infarction complicated by profound cardiogenic shock. J Crit Care. 2012;27:530.e1-11.

47. Asaumi Y, Yasuda S, Morii I, Kakuchi H, Otsuke Y, Kawamura A, et al. Favourable clinical outcome in patients with cardiogenic shock due to fulminant myocarditis supported by percutaneous extracorporeal membrane oxygenation. Eur Heart J. 2005;26:2185-92.

48. Elsharkawy HA, Li L, Esa WA, Sessler DI, Bashour CA. Outcome in patients who require venoarterial extracorporeal membrane oxygenation support after cardiac surgery. J Cardiothorac Vasc Anesth. 2010;24:946-51.

49. Wu MY, Lin PH, Lee MY, Tsai FC, Chu JJ, Chang YS, et al. Using extracorporeal life support to resuscitate adult postcardiotomy cardiogenic shock: Treatmen strategies and predictors of short-term and midterm survival. Resuscitation. 2010;81:1111-6.

50. Rastan AJ, Dege A, Mohr M, Doll N, Falk V, Walther T, et al. Early and late outcomes of 517 consecutive adult patients treated with extracorporeal membrane oxygenation for refractory postcardiotomy cardiogenic shock. J Thorac Cardiovasc Surg. 2010;139:302-11.

51. Park SJ, Kim SP, Kim JB, Jung SH, Choo SK, Chung CH, et al. Blood lactate level during extracorporeal life support as a surrogate marker for survival J Thorac Cardiovasc Surg. 2014;148:714-20.

52. Pagani F, Lynch W, Swaniker F, Dyke DB, Bartlett R, Koelling T, et al Extracorporeal life support to left ventricular assist device bridge to hear transplant: a strategy to optimize survival and resource utilization. Circulation. 1999;100(19 Suppl):II206-10.

53. Karamlou T, Gelow J, Diggs BS, Tibayan FA, Mudd JM, Guyton SW, et al Mechanic circulatory support pathways that maximize post-heart transplant survival. Ann Thorac Surg. 2013;95:480-5.

54. D'Alessandro C, Aubert S, Golmard SJ, Praschker BL, Luyt CE, Pavie A, et al. Extra-corporeal membrane oxygenation temporary support for early graft failure after cardiac transplantation. Eur J Cardiothorc Surg. 2010;37: 343-9.

55. Marasco SF, Vale M, Pellegrino V, Preovolos A, Leet A, Kras A, et al. Extracorporeal membrane oxygenation in primary graft failure after heart transplantation. Ann Thorac Surg. 2010;90:1541-7.

56. Listijono DR, Watson A, Pye R, Keogh AM, Kotlyar E, Spratt P, et al. Usefulness of extracorporeal membrane oxygenation for early cardiac allograft dysfunction. J Heart Lung Transplant. 2011;30:783-9.

57. Chen YS, Lin JW, Yu HY, Ko WJ, Jerng JS, Change WT, et al. Cardiopulmonary resuscitation with assisted extracorporeal life-support versus conventional cardiopulmonary resuscitation in adults with in-hospital cardiac arrest: an observational study and propensity analysis. Lancet. 2008;372:554-61.

58. Shin TG, Choi JH, Jo IK, Sim MS, Song HG, Jeong YK, et al. Extracorporeal cardiopulmonary resuscitation in patients with inhospital cardiac arrest: A comparison with conventional cardiopulmonary resuscitation. Crit Care Med. 2011;39: $1-7$.

59. Shin TG, Jo IJ, Sim MS, Song YB, Yang JH, Hahn JY, et al. Two-year survival and neurological outcomes of in-hospital cardiac arrest patients rescued by extracorporeal cardiopulmonary resuscitation. Int J Card. 2013;168:3424-30.

60. Maekawa K, Tanno K, Hase M, Mori K, Asai Y. Extracorporeal cardiopulmonary resuscitation for patients with out-of-hospital cardiac arrest of cardiac origin: a propensity-matched study and predictor analysis. Crit Care Med. 2013;41: 1186-96.

61. Kim SJ, Jung JS, Park JH, Park JS, Hong YS, Lee SW. An optimal transition time to extracorporeal cardiopulmonary resuscitation for predicting good neurologica outcome in patients with out-of-hospital cardiac arrest: a propensity-matched study. Crit Care. 2014;18:535.

62. Neumar RW, Shuster M, Callaway CW, Gent LM, Atkins DL, Bhanji F, et al. Part 1: Executive Summary: 2015 American Heart Association guidelines update for cardiopulmonary resuscitation and emergency cardiovascular care. Circulation. 2015;132(suppl):S315-67.

63. Philipp A, Arlt M, Amann M, Lunz D, Muller T, Hilker M, et al. First experience with the ultra compact mobile extracorporeal membrane oxygenation system Cardiohelp in interhospital transport. Interact Cardiovasc Thorac Surg. 2011 12:978-81.

64. Alwardt CM, Wilson DS, Alore ML, Lanza LA, DeValeria PA, Pajaro OE. Performance and safety of an integrated portable extracorporeal life support system for adults. J Extra-Corp Technol. 2015;47:38-42.

65. Roncon-Albuquerque R Jr, Basilio C, Figueiredo P, Silva S, Mergulhao P, Alves $\mathrm{C}$, et al. Portable miniaturized extracorporeal membrane oxygenation systems for H1N1-related severe acute respiratory distress syndrome: a case series. J Crit Care. 2012;27:454-63.

66. Extracorporeal Life Support Registry report (international summary). Ann Arbor: Extracorporeal Life Support Organization; 2008:30.

67. Lubnow M, Philipp A, Foltan M, Enger TB, Lunz D, Bein T, et al. Technical complications during veno-venous extracorporeal membrane oxygenation and 
their relevance in predicting a system-exchange-retrospective analysis of 265 cases. PLoS One. 2014;9:e112316.

68. Yu K, Long C, Hei F, Li J, Liu J, Ji B, et al. Clinical evaluation of two different extracorporeal membrane oxygenation systems: a single center report. Artif Organs. 2011;7:733-7.

69. Cheng R, Hachamovitch R, Kittleson M, Patel J, Arabia F, Moriguichi J, et al. Complications of extracorporeal membrane oxygenation for treatment of cardiogenic shock and cardiac arrest: a meta-analysis of 1,866 adult patients. Ann Thorac Surg. 2014;97:610-6.

70. Mazzeffi M, Greenwood J, Tanaka K, Menaker J, Rector R, Herr D, et al. Bleeding, transfusion, and mortality on extracorporeal life support: ECLS working group on thrombosis and hemostasis. Ann Thorac Surg. 2016;101:682-9.

71. Lidegran MK, Mosskin M, Ringertz HG, Frrenckner BP, Linden VB. Cranial CT for diagnosis of intracranial complications in adult and pediatric patients during ECMO: clinical benefits in diagnosis and treatment. Acad Radiol. 2007;14:62-71.

72. Kappetein AP, Head SJ, Genereux P, Piazza N, van Mieghem NM, Blackstone EH, et al. Updated standardized endpoint definitions for transcatheter aortic valve implantation. J Am Coll Cardiol. 2012;50:1438-54.

73. Cavarocchi NC, Pitcher HT, Yang Q, Karbowski P, Miessaue J, Hastings HM, et al. Weaning of extracorporeal membrane oxygenation using continuous hemodynamic transesophageal echocardiography. J Thorac Cardiovasc Surg. 2013;146:1474-9.

74. Brodie D, Bacchetta M. Extracorporeal membrane oxygenation for ARDS in adults. N Engl J Med. 2011;365:1905-14.

75. Kon ZN, Dahi S, Evans CF, Byrnes KA, Bittle GJ, Wehman B, et al. Long-term venovenous extracorporeal membrane oxygenation support for acute respiratory distress syndrome. Ann Thorac Surg. 2015;100:2059-63.

76. Kon ZN, Wehman PB, Gibber M, Rabin J, Evans CF, Rajagopal K, et al. Venovenous extracorporeal membrane oxygenation as a bridge to lung transplantation: successful transplantation after 155 days of support. Ann Thorac Surg. 2015;99:704-7.

77. Wang CH, Chou CC, Ko WJ, Lee YC. Rescue a drowning patient by prolonged extracorporeal membrane oxygenation support for 117 days. Am J Emerg Med. 2010;28:750.e5-7.

Key Words: extracorporeal membrane oxygenation, adult respiratory distress syndrome, extracorporeal cardiopulmonary resuscitation, cardiogenic shock, systematic review

\section{EDITORIAL COMMENTARY}

\section{Conventional extracorporeal membrane oxygenation therapy in the current era}

\author{
Akiko Tanaka, MD, PhD, and Takeyoshi Ota, MD, PhD \\ From the Department of Surgery, Section of Cardiac and Thoracic Surgery, The University of Chicago, \\ Chicago, Ill. \\ Disclosures: Authors have nothing to disclose with regard to commercial support \\ Received for publication March 13, 2016; accepted for publication March 14, 2016; available ahead of print April \\ 14, 2016. \\ Address for reprints: Takeyoshi Ota, MD, PhD, Department of Surgery, Section of Cardiac and Thoracic Surgery, \\ The University of Chicago, 5841 S Maryland Ave, MC5040, Chicago, IL 60637 (E-mail: tota@bsd.uchicago. \\ edu). \\ J Thorac Cardiovasc Surg 2016;152:32-3 \\ $0022-5223 / \$ 36.00$ \\ Copyright $₫ 2016$ by The American Association for Thoracic Surgery \\ http://dx.doi.org/10.1016/j.jtcvs.2016.03.040
}

We congratulate Squiers and colleagues ${ }^{1}$ on their comprehensive review of extracorporeal membrane oxygenation (ECMO) therapy in an adult population with a focus on patient outcomes of various clinical indications. The article also provides an organized summary of ECMO therapy with updated fundamental features, including cannulation techniques, ECMO circuits, and a monitoring strategy for proper oxygenation in peripheral venoarterial ECMO settings that enriches the knowledge of not only ECMO therapy professionals, but also readers who are unfamiliar with this technology.

ECMO use has markedly increased since the 2009 H1N1 influenza pandemic. ${ }^{2}$ After abatement of the pandemic, ECMO use continued to grow due to results from the

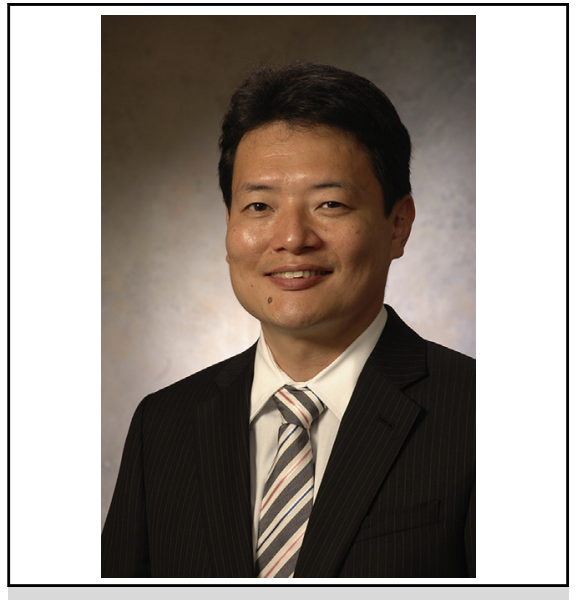

Takeyoshi Ota, MD, PhD

Central Message

Extracorporeal membrane oxygenation therapy plays an important role in salvage surgery and keeps evolving.

See Article page 20 .

Conventional Ventilator Support versus Extracorporeal Membrane Oxygenation for Severe Adult Respiratory 